\title{
A díade formação-atuação do tradutor-intérprete de Libras para o contexto educacional
}

DOl: http://dx.doi.org/10.21165/el.v50i2.3135

\section{Priscila Regina Gonçalves de Melo Giamlourenço' \\ Cristina Broglia Feitosa de Lacerda²}

\section{Resumo}

Responsável por tornar acessível e inteligível a comunicação entre surdos e ouvintes, ao tradutor-intérprete de Libras que atua no contexto educacional se pressupõem saberes e conhecimentos plurais haja vista a atuação ocorrer em áreas distintas e atuar na interface entre aspectos relativos aos processos tradutórios e de ensino e aprendizagem. A partir de um estudo de revisão de literatura, verifica-se que a formação continuada pode ser uma alternativa de encontro e espaço de debates e reflexões que sinalizam e consolidam as necessidades formativas que surgem da prática, das relações e dos processos tradutórios. A formação pode ainda ampliar os modos de percepção do profissional, além de favorecer conhecimentos específicos das áreas - da educação de surdos, das línguas e da educação inclusiva - também consciência do papel nesse contexto de atuação em que participa das relações pedagógicas ante os pressupostos e demandas relativas à inclusão educacional dos alunos surdos.

Palavras-chave: tradutor-intérprete de Libras; formação; educação.

1Universidade Federal de São Carlos (UFSCar), São Carlos, São Paulo, Brasil; primegi@yahoo.com.br; https://orcid.org/0000-0003-0787-6673;

2 Universidade Federal de São Carlos (UFSCar), São Carlos, São Paulo, Brasil; cbflacerda@gmail.com; https://orcid.org/0000-0002-3250-1374 


\section{La díada formación-actuación del traductor-intérprete de Libras para el contexto educativo}

\section{Resumen}

Siendo el responsable por volver accesible e inteligible la comunicación entre sordos y oyentes, al traductor-intérprete de Libras que actúa en el contexto educativo es asumido que construya saber y conocimientos plurales, en vista de trabajar en diferentes áreas, actuar en procesos de traducción e interpretación y también en el proceso educativo del estudiante sordo. Por medio de un estudio de revisión se desprende que la formación de modo continuado puede ser un encuentro y un espacio de debates para traer a la reflexión las necesidades formativas de la práctica, de las relaciones y de los procesos de traducción. La formación aún puede ampliar los modos de percepción del profesional, conciencia del rol en ese contexto de actuación en el que participa en las relaciones pedagógicas, además de promover conocimientos propios de las áreas, educación de sordos, lenguas e inclusión educacional.

Palabras-clave: Traductor-intérprete de Libras; formación; educación.

\section{Iniciando a reflexão}

O tradutor-intérprete ${ }^{3}$ de Libras, profissional responsável por tornar acessível e inteligível a comunicação entre os falantes da língua oral e da língua de sinais (SANTOS; LACERDA, 2015) pode atuar em diferentes contextos, entre eles, também garantido por lei, o educacional. A atuação desse profissional nesse espaço é de grande complexidade, haja vista as questões relativas aos processos de tradução e interpretação que desenvolve, aqui compreendidos como processos tradutórios ${ }^{4}$.

Os processos de tradução e interpretação são distintos entre si, distinguindo-se pelo modo como ocorrem, materializando-se a tradução, a partir de e para suporte escrito em diferentes formatos, e, a interpretação, a partir e pela oralidade também por meio de diferentes suportes e mesmo modalidade de língua, oral ou de sinais. A despeito da distinção entre os conceitos e atividades, nomeamos tradução e interpretação enquanto processos tradutórios uma vez que

\footnotetext{
3 Existem diferentes nomenclaturas para se referir a esse profissional (SALVADOR; LODI, 2018). Neste estudo, a partir da Classificação Brasileira de Ocupação, CBO 2614-25, optou-se por usar um dos sinônimos, a que se refere, tradutor-intérprete de Libras

4 Os processos de tradução e interpretação são distintos entre si. Para maiores informações sobre a diferença conceitual e prática entre traduzir e interpretar ver Sobral (2008) e Santos (2014).
} 
Caracteriza-se os processos de traduzir e interpretar pela produção de uma nova versão da intenção comunicativa em outra modalidade que não produzida inicialmente. Os textos produzidos por seus falantes primários são traduzidos ou interpretados passando pela inferência de sentidos do tradutor e intérprete para então serem inferidos por aqueles que recebem a mensagem final. (GIAMLOURENÇO, 2018, p. 24).

No âmbito escolar, além dos processos tradutórios, as relações educacionais e profissionais que o tradutor-intérprete de Libras estabelece com alunos, professores, pares e outros profissionais, bem como o processo e desenvolvimento educacional dos alunos surdos são ações inerentes à prática profissional nesse contexto de direito subjetivo e formação humana.

Segundo Santos e Lacerda (2015), os alunos surdos têm uma diferença linguística e "a presença do intérprete nas escolas é indispensável, pois é ele quem vai possibilitar o acesso às informações e conteúdos ministrados ao aluno surdo - mais que isso, esse profissional é o elo de sedimentação na construção de sentidos e conhecimentos" (SANTOS; LACERDA, 2015, p. 510-511).

O ambiente educacional, nos diferentes níveis, mostra-se complexo pelas questões educacionais atinentes a aspectos didáticos, metodológicos, curriculares e das relações sociais e culturais existentes que podem emergir na cotidianidade. Logo, fatores plurais atrelados a esse contexto podem favorecer ou não o profissional tradutor-intérprete de Libras na viabilização de práticas educacionais inclusivas.

A multiplicidade de fatores relativos aos processos de ensino e aprendizagem, nos quais os tradutores-intérpretes de Libras atuam nos contextos educacionais precisam ser refletidos buscando torná-los cada vez mais efetivos. Somente a inserção desse profissional em atenção às políticas de inclusão não garante a acessibilidade, sendo necessário que a condução do contexto educacional seja revista para que o ensino e aprendizagem sejam mediados pela língua de sinais, tendo essa língua cada vez mais centralidade nos processos e relações estabelecidas nesse espaço.

Diante disso, o presente artigo de revisão de literatura buscou apresentar o que os estudos recentes na área vêm discutindo em relação à díade formação-atuação do tradutor-intérprete de Libras no contexto educacional, compreendendo que a revisão dos trabalhos visibiliza aspectos dessa realidade e tem potencialidade para indicar possíveis alternativas visando contribuir com as práticas de atuação e ações de formação profissional. 
Estudos recentes abordam diferentes aspectos relacionados à atuação do profissional tradutor-intérprete de Libras, a partir dos quais é possível constatar a relevância da díade formação-atuação e vice-versa.

\section{Caminhos para a reflexão}

Apresenta-se um artigo de revisão de literatura, $A R L,{ }^{5}$ de literatura, o qual favorece a compreensão de problemáticas que circundam temáticas específicas (HOHENDORFF, 2014).

Os ARLs são textos nos quais os autores definem e esclarecem um determinado problema, sumarizam estudos prévios e informam aos leitores o estado em que se encontra determinada área de investigação. Também identifica relações, contradições, lacunas e inconsistências na literatura, além de indicar sugestões para a resolução de problemas. (HOHENDORFF, 2014, p. 40).

Buscou-se realizar a produção do presente artigo delimitando-se como tema a atuação do tradutor-intérprete de Libras no contexto educacional e a importância da formação profissional. Para tanto, realizou-se um levantamento bibliográfico na Biblioteca Digital de Teses e Dissertações, BDTD, a partir dos seguintes descritores: formação tradutor intérprete libras; formação tradutor libras; formação intérprete libras; formação intérprete educacional surdo; formação intérprete língua brasileira sinais; formação tradutor língua brasileira sinais; formação tradutor intérprete libras educação; formação intérprete surdos e formação tradutor surdos. Dessa revisão selecionou-se $23^{6}$ estudos que mais foram compreendidos enquanto relativos ao contexto da educação básica.

5 Os dados aqui utilizados relativos à formação para atuação do tradutor-intérprete de Libras no contexto educacional são resultantes de uma revisão de literatura do tipo sistemática feita para o estudo em desenvolvimento "Formação continuada e desenvolvimento profissional do Tradutorintérprete de língua de sinais na Educação a Distância (EaD)", o qual, embora com interesse nos aspectos gerais sobre a temática tem como foco a formação para atuação na Educação Superior.

6 A revisão inicial teve um total de 872 resultados, dos quais 739 foram inicialmente excluídos por não contemplarem os critérios de inclusão, resultando-se em 133 estudos. Após a leitura dos 133 resumos, buscou-se as pesquisas mais atinentes à temática do estudo supracitado, resultando-se em 38 estudos subdivididos em dois tópicos, sendo 23 estudos contemplando aspectos compreendidos como mais relativos à formação e atuação para a educação básica, e 15 estudos contemplando aspectos compreendidos como mais relativos à educação superior. Embora o estudo esteja em produção, considera-se a revisão desse levantamento bibliográfico, compreendendo-se que os dados já identificados podem contribuir à reflexão proposta neste trabalho. 
Observou-se que os estudos buscam investigar e discutir aspectos relevantes e relativos à prática desse profissional a partir de diferentes questões que merecem atenção, como questões da oficialização da Libras no contexto educacional, discussão e análise de trajetórias, práticas e relações de ensino nas quais esses profissionais atuam.

As reflexões acerca dos aspectos relativos à atuação e formação de profissionais nos estudos embasam-se em diferentes referenciais teórico-metodológicos, destacando-se que existe uma atenção e intenção em ouvir e dar voz aos profissionais. Em relação à abordagem, foram encontrados estudos em caráter exploratório do tipo investigativo, estudo de caso, pesquisas de campo, análises documentais e até mesmo estudo de abordagem microetnográfica, autoetnográfica e microgenética, indicando uma multiplicidade de metodologias de pesquisa implicadas.

Considera-se a importância de estudos buscarem conhecer as narrativas de profissionais sobre a prática. Com isso, torna-se possível discutir vivências de profissionais com formações distintas, sendo possível verificar que a formação influencia a atuação de intérpretes.

Visualizou-se que além de serem ouvidos profissionais tradutores-intérpretes, alguns estudos buscaram ouvir também alunos surdos, professores e gestão, coordenação e direção, sendo que, além de entrevistas, questionários, a realização de videogravações de situações reais de atuação emergiu como uma excelente estratégia metodológica para se refletir sobre os fatores que influenciam a atuação na esfera educacional.

\section{Questões relativas ao tradutor-intérprete de Libras $^{7}$ no contexto educacional}

\section{Apontamentos sobre a formação profissional}

A educação bilíngue de surdos, que pressupõe o uso da língua brasileira de sinais, Libras, como língua de instrução, e da língua portuguesa como segunda língua nos processos educacionais é uma das garantias estabelecidas a partir da oficialização da Libras no país (BRASIL, 2002, 2005). Segundo Santos e Lacerda (2015), esse modelo de educação, que pode ser compreendido como o mais adequado para a educação de alunos surdos, precisa contemplar suas necessidades de aprendizado por meio da Libras. Em suas palavras,

7 Embora tenhamos adotado a nomenclatura tradutor-intérprete de Libras, as formas de uso adotadas pelos autores dos estudos serão mantidas ao longo do artigo de revisão. 
Com a publicação da Lei 10.436 (BRASIL, 2002), que oficializou a Língua Brasileira de Sinais - Libras como forma de comunicação legal das comunidades surdas brasileiras, e do Decreto 5.626 (BRASIL, 2005), que determinou atribuições e o ingresso de profissionais especializados na educação de surdos, algumas mudanças passaram a ser exigidas no atendimento educacional dos surdos. (SANTOS; LACERDA, 2015, p. 508).

Diferentes aspectos referentes à oficialização vêm sendo discutidos, e um deles diz respeito à existência de problemas relativos à formação e perfil de profissionais que atuam em projetos dessa natureza nas redes regulares de ensino e inclusão educacional, havendo uma distância entre os textos oficiais que preveem a formação e as práticas desenvolvidas (VALIANTE, 2009).

Os agentes de uma escola bilíngue podem ser intérpretes de Libras, instrutor de Libras, professor bilíngue, professor regente da sala regular e professor do atendimento educacional especializado. Mesmo assim, a abordagem bilíngue, compreendida como alternativa para superação de barreiras nos processos de escolarização de alunos surdos pode sofrer prejuízos diante da carência na formação desses profissionais (SILVA, 2015), sendo esse um aspecto que merece bastante atenção.

Dentre os profissionais que atuam para efetivar práticas de educação inclusiva se encontram aqueles previstos para realizarem atendimento educacional especializado. Em relação à surdez são eles: profissionais com conhecimentos específicos no ensino da Língua Brasileira de Sinais (Libras), da Língua Portuguesa na modalidade escrita como segunda língua e tradutores-intérpretes de língua de sinais (Libras/Português) (TILS) (LACERDA, 2010, p. 135).

Considerando-se que na esfera educacional os intérpretes com diferentes perfis formativos atuam em diversas áreas do conhecimento, torna-se relevante que esses profissionais sejam qualificados e, para tanto, a formação cabe ser nesse contexto, pressupondo-se assim uma relação entre formação e atuação para a realização da atividade, contemplando-se áreas distintas (SOUZA, 2013).

A formação profissional tem demandas contínuas para todos os envolvidos no contexto escolar de inclusão educacional, que estabelecem diferentes formas de interação entre si e com o conjunto da escola. No tocante ao intérprete educacional, compreende-se uma diversificação de sua atuação em relação ao nível e áreas em que atua. Logo, além de políticas públicas em atenção às peculiaridades desse contexto, se fazem necessários cursos diferenciados de formação profissional (TUXI, 2009). 
Diante da atuação em diferentes áreas, a falta de formação específica e por especialidades acarreta limites na atuação, sendo a falta de contato prévio com o conteúdo e a ausência de competência técnica em Libras razões para o distanciamento da atuação de intérpretes em relação aos conhecimentos ensinados pelo professor (FERRARI, 2014; FERREIRA, 2015).

Essa relação formação-atuação precisa ser valorizada haja vista que esse profissional, além de mediar a comunicação, participa do processo educacional, o que demanda formação continuada em níveis distintos desde a graduação até a especialização na área de atuação (MELO, 2013).

No complexo contexto da sala de aula, além do processo de verter entre as línguas pela tradução e interpretação, a atenção à polissemia das línguas e de criação ou transcriação e coautoria junto ao professor são alguns dos fatores plurais que podem influenciar a atuação desse profissional e favorecer o processo de escolarização de alunos surdos (SANTOS, 2014). Em relação à transcriação relativa à versão de uma língua para outra,

Pode-se compreender a transcriação como aquilo que excede à tradução e/ ou interpretação, os limites das línguas, com o intuito de compensar as perdas ocorridas durante esse processo. Seria a transformação da informação original (em um sistema semiótico), em outro texto, também original e autônomo (em outro sistema semiótico), visto que é permitido ao tradutor e ao intérprete certa "interferência" no conteúdo. (SANTOS; LACERDA, 2015, p. 516).

Sua presença não é neutra nesse espaço. Estabelece relações de troca, participa das relações de ensino e da dinâmica escolar, exercendo interferência na prática pedagógica, bem como na condução educacional, aspectos que precisam ser contemplados nas formas de se conceber a formação específica desse profissional (MARTINS, 2013).

Destarte, cada vez mais se torna relevante investir na formação, principalmente, porque sua atuação está atrelada à função de ensinar, logo, ocupa um espaço pedagógico (SUZANA, 2014). Entretanto, profissionais intérpretes de Libras podem desconhecer aspectos da educação de surdos, inclusive históricos, e, em atuação, nem sempre participam do planejamento junto ao professor (ARAÚJO, 2011), indicando no campo a persistência de uma falta de compreensão acerca dos papéis assumidos no processo educacional junto aos alunos surdos (SOUZA, 2018), o que mais uma vez justifica a importância da formação profissional nesse contexto, no qual

É fundante que a Língua Brasileira de Sinais (Libras) circule, sem limitações, no todo da escola, que não fique restrita aos alunos surdos e intérpretes, que haja o reconhecimento da Libras como fator essencial ao desenvolvimento e 
à construção de pertença para os surdos, o que denota clara predisposição da escola a acolher estes Outros, reconhecendo neles sua diferença sociolinguística e singularidades. Além do que isso é determinante para o planejamento e a vivência de um trabalho responsável diante de todos os envolvidos em projetos de inclusão educacional, visto que a consciência e o compromisso em relação a estes aspectos nos tornam mais aptos ao ato responsivo, em projetos para a escolarização de surdos, mas também de tantos outros. (MENEZES; LACERDA, 2015, p. 254).

A relação com a língua de sinais também é refletida nos estudos, mostrando que diferentes questões podem ser contempladas em propostas de formação. Uma delas diz respeito à produção de sentidos pela corporeidade. Destaca-se sua relevância como instância de produção de sentidos para além do uso do movimento do corpo, de seus membros e conhecimento da gramática, evidenciando ser necessário ao interpretar emoção, clareza e sentido propiciados pela corporeidade (SILVA, 2009).

Considerando-se esses elementos, torna-se necessária revisão e reavaliação de questões plurais relativas à atuação, não restritas à formação profissional, mas também questões relativas ao estabelecimento de critérios para a contratação, bem como a importância de capacitação profissional para embasamento das práticas no contexto educacional (ARAÚJO, 2011).

Os intérpretes formam uma nova categoria de profissionais na inclusão escolar de alunos surdos e nos processos de ensino e aprendizagem, nesse sentido, precisam compreender o significado da inclusão educacional, e a formação profissional quando contínua e, em conjunto para professores e intérpretes, favorece reflexões sobre a função e papel a serem desenvolvidos na escola (SOUZA, 2018).

Com relação ao trabalho em sala de aula, ressalta-se que este envolve linguagem, escolhas por parte do IE, reflexão, relações sociais com diferentes sujeitos, e participação no processo de ensino e aprendizagem. Para além da tarefa de transposição de uma língua à outra, a atuação do IE abarca a construção de enunciados e sentidos presentes na mensagem enunciada pelo(s) (muitos) outro(s), respeitando-se os conteúdos e gêneros discursivos em questão, além de abranger diversas áreas de conhecimento. (SANTOS; LACERDA 2015, p. 512).

A formação específica para quem atua no espaço educacional, a relação entre professor e intérprete na aprendizagem de alunos surdos e questões relativas à interação do aluno com o professor podem ser consideradas como demandas a serem contempladas em ações de formação profissional (FERRARI, 2014). A formação de intérpretes precisa, assim, subsidiar o entendimento acerca de questões relativas à educação do surdo, refletindo sobre questões relacionadas à inclusão educacional de surdos destacando as 
relações entre professores regentes e os intérpretes que compartilham a sala de aula para atuação (SOUZA, 2018).

Se faz necessária ainda a compreensão por parte das instituições e mesmo secretarias de educação que esse profissional precisa fazer parte como integrante do processo de ensino e aprendizagem, e aspectos relativos à função e ao papel merecem atenção em função da qualidade almejada da escolarização do aluno surdo, mas também em virtude da sobrecarga física e psicológica que pode decorrer da atuação (VIEIRA, 2017).

\section{Apontamentos relativos à consciência profissional e desafios da atuação}

Como se vê a partir das investigações dos autores apresentadas neste estudo, a atuação do intérprete no contexto educacional está estritamente relacionada com a escolarização de surdos em parceria com o professor, tanto para acessibilidade linguística como enquanto participante ativo do processo educacional desses alunos.

$\mathrm{Na}$ interface com a necessidade de formação, visualiza-se que as pesquisas discutem também questões relativas a atitudes, identidade e consciência profissional. A atuação atrela-se à escolarização do aluno surdo, e nisso está uma responsabilidade relativa à forma de se conceber e compreender a atividade e o papel na formação do aluno (MENEZES, 2014).

A formação continuada dos profissionais favorece a consciência profissional em relação a si, consigo, e em relação ao outro e para as relações com o outro. Mas, além da formação, constata-se a importância de momentos de reflexão e estudo do intérprete educacional na prática e para a prática (SOARES, 2018). Destaca-se ainda que a formação, sempre relevante, favorece a consciência do papel nesse espaço de atuação em que precisa estabelecer uma relação humana e profissional com o professor (MELO, 2013).

Os profissionais atribuem sentidos acerca da prática que desenvolvem, das relações e das atividades, de seu papel e responsabilidade relativos ao processo de escolarização, e precisam ampliar a percepção quanto à atuação profissional em sala de aula (SOARES, 2018).

Podem compreender a importância do suporte ao corpo docente, de fazer parte da equipe e ter parceria com o professor. Destaca-se ainda que a formação, profissionalização e politização precisam ser buscadas constantemente, tanto de maneira individual como coletiva, haja vista os aspectos políticos, ideológicos e filosóficos ante a constituição da identidade profissional (MENEZES, 2014). 
O tradutor intérprete de Libras, em função também de concepções e práticas, está num processo de construção e reconstrução de sua identidade, buscando se reconhecer e ser reconhecido nesse espaço de atuação, que, por sua complexidade, envolve competências relacionadas à tradução e também específicas da área da educação. Nesse sentido, a formação pode apontar ferramentas importantes a serem utilizadas no trabalho. (CARVALHO, 2015).

Questões relacionadas à identidade e consciência profissional estão atreladas à relação do profissional consigo e com as relações estabelecidas no contexto de atuação, como em relação ao surdo e à sua língua. O aprimoramento da formação dos intérpretes de língua de sinais é também uma forma de intervenção nas relações nas línguas e nas relações dos falantes com elas, dado que as relações ainda podem ser marcadas por vieses coloniais e atitudes paternalistas. A este profissional, mediador linguístico e cultural, torna-se relevante a formação que o leve a refletir a respeito de atitudes em relação ao surdo e à língua de sinais (PASSOS, 2010).

A reflexão em relação ao posicionamento profissional é fundamental uma vez que as práticas precisam ser revistas pelos profissionais que atuam com esse público, e um dos fatores relativos às práticas educacionais direcionadas aos surdos refere-se às metodologias e estratégias para o ensino de alunos surdos que ainda podem ser pensadas da mesma forma como o são para ouvintes (SOUZA, 2016).

A condição e diferença linguística do aluno surdo em relação à leitura, interpretação e escrita na língua portuguesa, por exemplo, mostra-se como um elemento que indica a importância e necessidade de consciência profissional e da importância da profissão, qualificação e formação continuada de docentes e intérpretes na área da educação de surdos para a melhoria nos processos de ensino e aprendizagem e adoção de metodologia de ensino que atenda às necessidades dos alunos surdos (SOUZA, 2016).

A formação na área e a evolução na profissão são garantias legais, inclusive, de representação da categoria. Existe na atualidade uma expansão nas possibilidades de formação, de modo que aqueles sem relação com a comunidade podem se inserir nesse campo para atuar (ESMERIO, 2019), bem como aqueles que têm contato desde a infância - CODA $^{8}$ - filhos de pais surdos, que, membros da comunidade, buscam tornarse profissionais (SILVA, 2016).

A constituição pela interação com a comunidade é muito relevante e há aqueles que passam a estabelecer um envolvimento e relação profissional e outros que compreendem essa relação como importante para o trabalho. Há profissionais que se inserem nesse

8 A sigla CODA, em inglês, Children Of Death Adultos, refere-se a filhos (ouvintes) de pais surdos. 
campo, sem uma relação prévia, o que difere dos primórdios da atuação. Todavia, até mesmo para aqueles que fazem parte da comunidade surda há interesse pela formação profissional (SILVA, 2016; ESMERIO, 2019)

A formação desse profissional tem sido oferecida em nível superior no país, embora ainda de maneira escassa. Destaca-se a importância da reflexão sobre as formações ofertadas, comumente para uma atuação generalista, e a relevância e necessária formação, capacitação e formação continuada por especialidades ou áreas específicas do conhecimento (FERREIRA, 2015). Entretanto,

Os poucos cursos propostos no Brasil, tanto pelas IES públicas como pelas privadas, oferecem formação para a atuação do TILS em todas as áreas. Entretanto, na atualidade, a demanda mais importante por este profissional está na área educacional e os estudantes nem sempre recebem formação aprofundada para atuar neste campo e refletir sobre as especificidades de seu papel nos diferentes níveis de ensino. Por este motivo, defende-se que a formação dos TILS enfatize também as questões que envolvam o campo educacional e os princípios da educação inclusiva bilíngue, na medida em que este profissional terá papel fundamental no processo de aprendizagem das pessoas surdas. (LACERDA, 2010, p. 144-145).

Ainda sobre cursos de formação profissional, em nível de graduação, se faz necessário refletir acerca do currículo, especificamente acerca dos conhecimentos linguísticos na Libras, uma vez que pode haver uma fragilidade em relação aos conteúdos delimitados no ementário, e que mesmo após o estudante ter cursado níveis considerados avançados de Libras, não há um sentimento de estar preparado para atuação (LINDEN, 2017).

A partir dos estudos refletidos até aqui se torna possível perceber o desafio para a concepção de ações e propostas de formação profissional inicial e continuada de TILS. A educação apresenta-se como um campo amplo, com um público diverso, inclusive, no que se refere à surdez, e é sempre importante destacar que "a Educação Inclusiva não pode estar restrita ao acesso dos alunos às escolas ou à língua, mas é imperiosa reflexão sobre a formação dos profissionais que atuam com esses alunos e o direcionamento de projetos políticos pedagógicos para uma ação educacional efetiva" (LACERDA, 2010, p. 136).

Um profissional pode atuar, por exemplo, junto a estudantes indígenas surdos, o que pressupõe especificidades a serem contempladas em sua atuação e formação, como aspectos relativos à inclusão e formas de comunicação da criança surda indígena no contexto familiar e escolar. O intérprete, embora possa ser apontado como facilitador pelos professores indígenas, necessita de formação específica para essa realidade (LIMA, 2013). 
Destaca-se ainda, da parte desses profissionais, o reconhecimento das dificuldades em relação à capacitação no tocante à educação indígena no que concerne a questões políticas e a aspectos culturais e linguísticos que precisam ser contemplados nas práticas interpretativas em atenção à educação escolar e educação especial nas escolas comuns (ARAÚJO, 2018).

\section{Considerações parciais}

Como visto, a formação pode ampliar os modos de percepção do profissional na compreensão de si, do trabalho que desenvolve, das relações com professores e alunos, e de sua relação com a língua de sinais. A formação do tradutor-intérprete de Libras pode ser compreendida como um requisito fundamental para o desenvolvimento do trabalho no contexto educacional.

Questões como formação profissional, consciência e identidade profissional e aspectos da prática, apresentadas nas seções do presente estudo, são investigadas e refletidas a partir de trabalhos que permitem, por seus aspectos teórico metodológicos, perceber que a atividade tem sido cada vez mais refletida e a voz dos profissionais ouvida.

Mesmo assim, os estudos também permitem a inferência de lacunas relativas à essa díade, as que refletidas podem ampliar as possibilidades de reflexão acerca da formação e atuação, logo de escolarização de alunos surdos que fazem uso da Libras e necessitam dessa mediação, principalmente, como refletem Lacerda, Gracia e Jarque (2020), pelo papel da Libras na constituição de sujeito de alunos surdos, capaz de favorecer potencialmente seu desenvolvimento educacional.

Visualiza-se nos estudos apresentados a necessidade de formação contínua para todos os profissionais da educação de surdos, inclusive em conjunto, por exemplo, professores e tradutores-intérpretes. Para esses, especificamente, dada sua atuação em áreas distintas do conhecimento, a complexidade da atividade nesse contexto e também do processo tradutório, se faz necessária a formação contínua.

A formação pode favorecer, além de conhecimentos específicos das áreas - da educação de surdos, das línguas e da educação inclusiva - também consciência do papel nesse contexto de atuação em que participa das relações pedagógicas. Contemplar questões da prática nas ações de formação se faz necessário para aproximar a atuação e a formação, as experiências vividas na realidade educacional com experiências sistematizadas pelo investimento teórico e conceitual com a participação e valorização do fazer profissional.

A formação continuada de profissionais pode ser uma alternativa de encontro e espaço de debates e reflexões que sinalizam e consolidam as necessidades formativas que 
surgem da prática, das relações e dos processos tradutórios. Sem esgotar a necessidade de se refletir sobre a formação do tradutor-intérprete de Libras para atuação na educação básica, é possível destacar o potencial da formação para a atuação profissional ante os pressupostos e demandas relativas à inclusão educacional dos alunos surdos.

\section{Agradecimentos}

O presente trabalho foi realizado com apoio da Coordenação de Aperfeiçoamento de Pessoal de Nível Superior - Brasil (CAPES) - Código de Financiamento 001.

\section{REFERÊNCIAS}

ARAÚJO, J. R. O papel do intérprete de libras no contexto da educação inclusiva: problematizando a política e a prática. 2011. Dissertação (Mestrado em Educação) Centro de Ciências Humanas, Letras e Artes, Universidade Federal da Paraíba, João Pessoa, 2011.

ARAÚJO, B. R. N. A escolarização de indígenas terena surdos: desafios e contradições na atuação do tradutor intérprete de línguas de sinais - TILS. 2018. Dissertação (Mestrado em Educação) - Faculdade de Artes, Letras e Comunicação, Universidade Federal do Mato Grosso do Sul, Campo Grande, 2018.

BRASIL. Lei 10.436, de 24 de abril de 2002. Dispõe sobre a Língua Brasileira de Sinais - Libras e dá outras providências. Disponível em: http://www.planalto.gov.br/ccivil_03/ leis/2002/l10436.htm Acesso em: 25 jun. 2021.

BRASIL. Decreto 5626, de 22 de dezembro de 2005. Regulamenta a Lei n. 10.436, de 24 de abril de 2002, que dispõe sobre a Língua Brasileira de Sinais - Libras e o art. 18 da Lei n. 10.098, de 19 de dezembro de 2000. Disponível em: http://www.planalto.gov.br/ ccivil_03/_ato2004-2006/2005/decreto/d5626.htm Acesso em: 25 jun. 2021.

CBO 261425 - Intérprete de língua de sinais. Classificação Brasileira de Ocupações. Disponível em https://www.ocupacoes.com.br/cbo-mte/261425-interprete-de-lingua-desinais. Acesso em: 14 dez. 2020.

CARVALHO, G. L. A identidade do profissional tradutor e intérprete de língua brasileira de sinais - libras: das suas concepções às suas práticas. 2015. Dissertação (Mestrado em Ciências da Educação) - Universidade Lusófona de Humanidades e Tecnologias, Lisboa, 2015. 
ESMERIO, J. M. M. A produção de modos de ser o tradutor e intérprete de língua brasileira de sinais. 2019. Dissertação (Mestrado em Educação) - Centro de Educação, Universidade Federal de Santa Maria, Santa Maria, 2019.

FERRARI, A. C. M. Atuação do tradutor intérprete de Libras na aprendizagem matemática de surdos no Ensino Fundamental. 2014. Dissertação (Mestrado em Educação) - Faculdade de Letras, Universidade Federal de Minas Gerais, Belo Horizonte, 2014.

FERREIRA, D. Um estudo comparativo de currículos de curso de formação de tradutores e intérpretes de libras-português no contexto brasileiro. 2015. Dissertação (Mestrado em Estudo da Tradução) -Centro de Comunicação e Expressão, Universidade Federal de Santa Catarina, Florianópolis, 2015.

GIAMLOURENÇO, P. R. G. M. Tradutor e Intérprete de Libras: construção da formação profissional. 2018. Dissertação (Mestrado em Educação Especial) - Centro de Educação e Ciências Humanas, Universidade Federal de São Carlos, São Carlos, 2018.

HOHENDORFF, J. V. Como escrever um artigo de revisão de literatura. In: KOLLER, S. H.; COUTO, M. C. P. de P.; HOHENDORFF, J. V. (org.). Manual de Produção Cientifica. Porto Alegre: Penso, 2014. p. 39-54.

LACERDA, C. B. F. Tradutores e intérpretes de Língua Brasileira de Sinais: formação e atuação nos espaços educacionais inclusivos. Cadernos de Educação, v. 36, p. 133-153, 2010. Disponível em: https://periodicos.ufpel.edu.br/ojs2/index.php/caduc/article/ viewFile/1604/1487. Acesso em: 02 fev. 2017.

LACERDA, C. B. F; GRACIA, M.; JARQUE, M. J. Línguas de Sinais como Línguas de Interlocução: o lugar das atividades comunicativas no contexto escolar. Rev. bras. educ. espec., Bauru, v. 26, n. 2, p. 299-312, jun. 2020.

LINDEN, V. C. Como diz Libras em libras? A comunicação do conhecimento linguístico na formação de tradutores e intérpretes de Libras. 2017. Dissertação (Mestrado em Linguística) - Centro de Comunicação e Expressão, Universidade Federal de Santa Catarina, Florianópolis, 2017.

LIMA, J. M. S. A Criança indígena surda na cultura Guarani-Kaiowá: um estudo sobre as formas de comunicação e inclusão na família e na escola. 2013. Dissertação (Mestrado em Educação) - Faculdade de Educação, Universidade Federal da Grande Dourados, Dourados, 2013. 
MARTINS, V. R. O. Posição-Mestre: desdobramentos foucaultianos sobre a relação de ensino do intérprete de língua de sinais educacional. 2013. Tese (Doutorado em Educação) - Instituto de Estudos da Linguagem, Universidade Estadual de Campinas, Campinas, 2013.

MELO, A. V. S. Formação e atuação do tradutor intérprete de libras em sala de aula. 2013. Dissertação (Mestrado em Educação) - Universidade Tiradentes, Aracaju, 2013.

MENEZES, A. M. C. Diálogos com tradutores-intérpretes de língua de sinais. 2014. Tese (Doutorado em Ciências Humanas) - Centro de Educação e Ciências Humanas, Universidade Federal de São Carlos, São Carlos, 2014.

MENEZES, A. M. C.; LACERDA, C. B. F. Tradutores-intérpretes de línguas de sinais: funções e atuação nas redes de ensinos. Revista educação especial (UFSM), v. 30, p. 251262, 2017.

PASSOS, G. C. R. Os intérpretes de língua de sinais: atitudes frente à língua de sinais e às pessoas surdas. 2010. Dissertação (Mestrado em Linguística) - Centro de Comunicação e Expressão, Universidade Federal de Santa Catarina, Florianópolis, 2010.

SALVADOR, S. J. L.; LODI, A. C. B. Resoluções do Estado de São Paulo e o Professor Interlocutor: implicações para a educação dos surdos. Rev. bras. educ. espec., Bauru, v. 24, n. 2, p. 277-292, abr. 2018.

SANTOS, L. F. O fazer do intérprete educacional: práticas, estratégias e criações. 2014. Tese (Doutorado em Ciências Humanas) - Centro de Educação e Ciências Humanas, Universidade Federal de São Carlos, São Carlos, 2014.

SANTOS L. F.; LACERDA, C. B. F. Atuação do intérprete educacional: parceria com professores e autoria. Cadernos de Tradução, v. 35, n. 2, p. 78-112, 2015.

SILVA, C. J. C. A corporeidade da intérprete de língua de sinais na percepção dos sentidos produzida por interlocutores surdos. 2009. Dissertação (Mestrado em Educação) Faculdade de Educação, Universidade de Passo Fundo, Passo Fundo, 2009.

SILVA, A. R. O desafio do bilinguismo para alunos surdos no contexto da inclusão: o caso de uma escola municipal do Rio de Janeiro. 2015. Dissertação (Mestrado em Educação) Faculdade de Letras, Universidade Federal do Rio de Janeiro, Rio de Janeiro, 2015. 
SILVA, M. M. da. Codas tradutores e intérpretes de língua de sinais brasileira: percurso para o profissionalismo. 2016. Dissertação (Mestrado em Estudos da Tradução) - Centro de Comunicação e Expressão, Universidade Federal de Santa Catarina, Florianópolis, 2016.

SOBRAL, A. Dizer o 'mesmo' a outros: ensaios de tradução. São Paulo: Special Book Services Livraria, 2008.

SOARES, N. G. Intérprete educacional de Libras: afirmações e conflitos da profissão. 2018. Dissertação (Mestrado em Educação) - Universidade Federal da Fronteira do Sul, Erechim, 2018.

SOUZA, R. A. Preconceito nas relações de trabalho: um estudo com professores e tradutores/intérpretes de libras. 2018. Dissertação (Mestrado em Psicologia) Universidade Federal de Mato Grosso do Sul, Campo Grande, 2018.

SOUZA, I. S. R. Estratégias e metodologias para o ensino de língua portuguesa para surdos em Aracaju/SE. 2016. Dissertação (Mestrado em Educação) - Universidade Federal de Sergipe, São Cristóvão, 2016.

SOUZA, M. R. Narrativas dos intérpretes de língua brasileira de sinais que atuam no contexto do ensino fundamental. 2013. Dissertação (Mestrado em Estudos da Tradução) - Centro de Comunicação e Expressão, Universidade Federal de Santa Catarina, Florianópolis, 2013.

SUZANA, E. R. B. O tradutor/intérprete de libras em contextos de inclusão escolar: perspectivas em uma rede municipal do Rio Grande do Sul. 2014. Dissertação (Mestrado em Educação) - Universidade Federal do Rio Grande do Sul, Porto Alegre, 2014.

TUXI, P. A atuação do intérprete educacional no ensino fundamental. 2009. Dissertação (Mestrado em Educação) - Instituto de Letras, Universidade de Brasília, Brasília, 2009.

VALIANTE, J. B. G. Língua Brasileira de Sinais: reflexões sobre a sua ofıcialização como instrumento de inclusão dos surdos. 2009. Dissertação (Mestrado em Linguística) Instituto de Estudos da Linguagem, Universidade Estadual de Campinas, Campinas, 2009.

VIEIRA, M. I. I. A atuação do intérprete educacional da libras nas escolas de ensino fundamental de Limoeiro do Norte-CE. 2017. Dissertação (Mestrado em Educação e Ensino) - Universidade Estadual do Ceará, Limoeiro do Norte, 2017. 